\title{
Assessing the indoor comfort conditions through energy performance and CFD analyses for a traditional masonry chimney
}

\author{
H. Tuğçin Kırant ${ }^{\text {iD }}$, Hatice Sözer*iD \\ Istanbul Technical University, Energy Institute, Istanbul, Turkey
}

\begin{abstract}
Energy performance and heat flux of a traditional heating system, called Russian masonry stove, was analyzed with a comparative study based on its original S-shaped chimney design and high specific heat value firestone material. The study aims to improve building energy performance by taking advantage of traditional techniques. The paper was structured within three stages; architectural modeling of the stove, to identify and understand the architecture of the system, energy performance modeling of the stove, to specify the system performance and CFD modeling of the stove, to analyze the system's performance influence on indoor comfort conditions. Results were compared with the steel casting straight chimney stove which is commonly used in contemporary architecture. The results showed that the influence of the Russian stove's unique specifications enabled acquiring the better level of desired indoor comfort conditions. The installation of the Russian stove to the contemporary buildings would be suggested in respect of providing the level of thermal comfort and energy performance.
\end{abstract}

\section{Keywords}

Russian stove; Computational fluid dynamics; Energy efficiency; Building energy performance; Firestone Received: 06 November 2020; Accepted: 14 December 2020

ISSN: 2630-5771 (online) $\odot 2020$ Golden Light Publishing All rights reserved.

\section{Introduction}

Energy usage rises along with population growth, industrial developments, and consumption habits. As the energy demand increases day by day, authorities try to find better solutions. Foundations, corporations, and research institutes create financial support to increase the awareness of energy efficiency and find new technics to reduce energy consumption. Thus, it should be examined by different sectors such as industry, residential, transport, services, and agriculture. The statistical results show that the residential sector is the second greatest sector by $26 \%$ of the overall consumption in Europe [1]. This consumption comes from space heating by end-use that equal to $65 \%$ [2].

Varied type of heating systems is used in the homes by the end-users. In the literature, there are many types of research focus on commonly operated systems. Apart from the often preferred heating systems, some unique systems are needed to be investigated to discover their distinctiveness to improve the heating system's efficiency. The stove is one of them that is used less than other conventional systems. Wood, coal, or bio-ethanol are some of the fuel types to perform the combustion in this system. However, wood is the most chosen fuel type for stoves. There are several

\footnotetext{
* Corresponding author

Email: sozerh@itu.edu.tr
} 
kinds of wood-burning stove designs that change regionally based on cultural influences. Regional climate conditions affect the preferred material based on local sources. In addition to this, the architectural concept of the regions determines the general structure of the stoves.

The rise of energy and fuel consumption indicates the importance of heating system analysis. Hence, a traditional heating system, a woodburning Russian stove was examined in this study based on its material and the unique chimney design. The research includes energy performance study and computational fluid dynamics (CFD) analysis.

The stove structure has four main parts as; main body, chimney, body opening, material. It is designed by different architectural styles on the exterior surfaces. Besides that, their internal designs show distinct differences as represented above in Fig. 1. The heat distribution is affected through the building environment by these different models. The combustion section of the stoves is the first location of the heat transfer, and the heated air rises towards to chimney outlet. Therefore, the internal design mainly manages the path of the warmed air, then it influences the heat transfer.

In the literature, there is limited academic research in the field of Russian masonry stoves which studies the importance of material's feature, occupant behavior, chamber size, and chimney design of the other stoves. Øyvind Skreiberg and

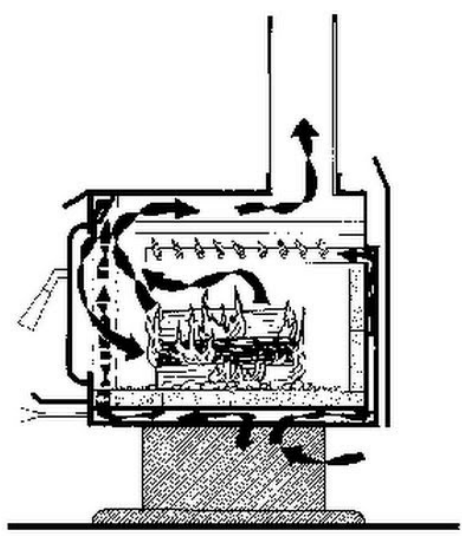

a. Ordinary stoves
Laurent Georges investigated the heat release by a comparative study of cast iron stove and soapstone stove [5]. The study shows that the thermal mass specification of the soapstone procures a longer period of heating temperature containment. Besides, Phase Change Material (PCM) reduces the peak heat by $53 \%$ and extends the period of heat release by $43 \%$. Georges, Skreiberg, and Novakovic analyze the stove operation in a twostory passive house [6]. The stove operation may cause overheating as the heating need of the passive houses is less than the ordinary building types. Different types of stoves were investigated regarding their power levels such as $6 \mathrm{~kW}, 8 \mathrm{~kW}$, and $12 \mathrm{~kW}$. If a $6 \mathrm{~kW}$ or $8 \mathrm{~kW}$ stove is used, the stove should have power modulation to prevent overheating. However, if a $12 \mathrm{~kW}$ stove is chosen, the overheating cannot be avoided even it has power modulation. The research of Tabet, Fichet, and Plion investigates increasing the stove efficiency while reducing the emissions [7]. It was indicated that the burning chamber volume should be enlarged to obtain higher residence times of the flue gases. Another study evaluates the efficiency of gasifier stove by experimental and CFD analysis. The efficiency of the stove for overall flaming mode and the impact of convective and radiation effects are investigated [8]. An optimization using the numerical model to increase the efficiency of the logwood boiler by the CFD model was studied [9].

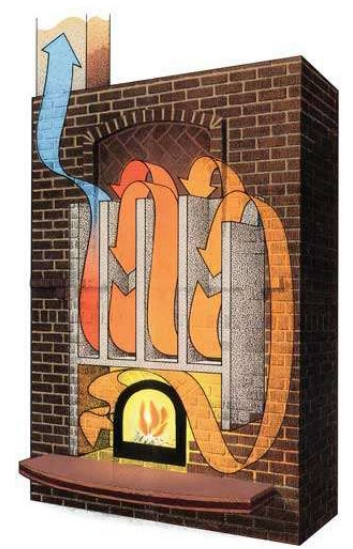

b. Russian stove

Fig. 1. Air movement 
The boiler efficiency increased while $\mathrm{CO}_{2}$ was reduced. The effect of chimney design was investigated experimentally [10]. Two different chimney diameters were compared. A costeffective way the increment of stove efficiency by chimney design was analyzed by another study [11]. Research reveals out that the thermal efficiency can be risen using an annular chimney. Also, wood fuel can be saved by the installation of an outer chimney component.

Department of Architecture - the University of Oregon examined one of the Russian stoves (Fig. 2). They studied the energy performance of contraflow masonry stoves by comparing the net heat loss of the home with the consumed energy by stove [12]. They revealed out the relation of outdoor air temperature and average inside temperature for 8 days while operating the contraflow masonry stove.

This analysis was performed in a family building at Pleasant Hill Oregon. The results output that the indoor air temperature was settled averagely at $18.8^{\circ} \mathrm{C}$ when the outside temperature ranges from $0{ }^{\circ} \mathrm{C}$ to $11{ }^{\circ} \mathrm{C}$. The stove was lit one time a day, but on some days, the occupant didn't need to operate the stove based on the outside temperate. Approximately, $110 \mathrm{~kg}$ of wood was utilized, and the heat load amount was found as 2.6 $\mathrm{kW}$. Regarding the study, $2.04 \mathrm{~kW}$ net heat loss was calculated in the building. Therefore, the efficiency of the stove was obtained as $79.5 \%$.

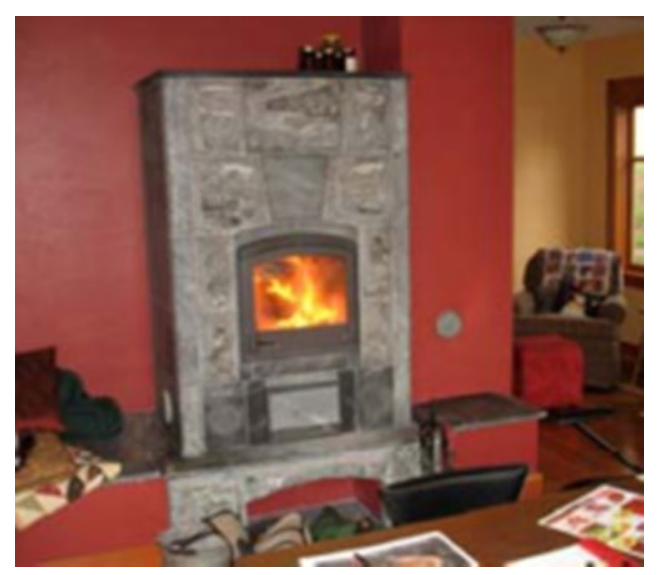

Fig. 2. Contraflow masonry heater [12]
The given studies of literature present the results of the final indoor temperature and show the efficiency based on the outdoor temperature data in real-time. In addition to this, they evaluate the chimney design's effect on fuel consumption. However, these researches are not enough to evaluate the indoor thermal conditions and occupant thermal comfort together, comprehensively. Therefore, this research investigates them based on the following context:

- CFD analysis is used to examine the heat distribution for the Russian stove heating system considering PMV

- The generated temperature gradient is specified by the simulation

- The energy performance is analyzed

The motivation of the study is to take advantage of traditional techniques to utilize them in modern architecture for energy efficiency. Therefore, the entire paper was structured around this concept. The paper has three stages to analyze not only energy efficiency but also its effect on indoor comfort conditions. These stages were developed as; architectural modeling that shows the details of the stove and its location inside of the building, energy modeling that specifies the materials thermal capacities and their effect on energy performance, CFD modeling that produce the heat distribution of the traditional Russian stove.

\section{Method}

In this research, energy performance and CFD analysis were used to perform the performance assessments of the Russian stove. Hence, the research was started by creating the 3D model of the stove with its unique design as a base to have accurate results from both energy and CFD models. The stages and applied simulation models are shown in Fig. 3.

In the first stage, the building with the stove design was modeled by the Autodesk ${ }^{\circledR}$ Revit program. In the second stage, the Energy Performance Model was developed by importing the $3 \mathrm{D}$ model to DesignBuilder ${ }^{\circledR}$. Information such as thermal characteristics of building materials, user 


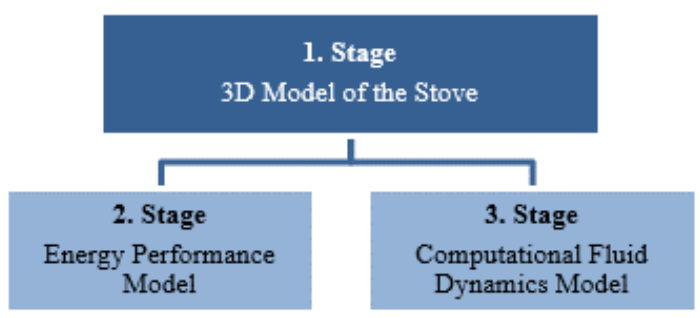

Fig. 3. The relation of the simulation models

schedule, thermal regulations, and standards are specified and assigned to the model. In the third stage, the $3 \mathrm{D}$ model is imported to Autodesk ${ }^{\circledR}$ CFD.

In the first stage, the building with the stove design was modeled by the Autodesk ${ }^{\circledR}$ Revit program. In the second stage, the Energy Performance Model was developed by importing the $3 \mathrm{D}$ model to DesignBuilder ${ }^{\circledR}$. Information such as thermal characteristics of building materials, user schedule, thermal regulations, and standards are specified and assigned to the model. In the third stage, the $3 \mathrm{D}$ model is imported to Autodesk ${ }^{\circledR}$ CFD.

In the CFD simulation, the Low Re $\mathrm{k}$ epsilon turbulence model was used. This turbulence model examines the natural convection circulation. Furthermore, it enables the evaluation of the rarely formed high number Reynold number flow, as well [13]. Thus, it can analyze both of the flows together by this turbulence model. In addition to the turbulence models, the suitable advection scheme, the Modified Petrov-Galerkin solution method was preferred. This solution method uses the secondorder- third order differential equations and provides stability on energy balance and natural convection [14]. Also, it is appropriate for the secondary flow actions which take place in this study based on the chimney's S-shaped path. The radiation effect is involved by the grey body model in the simulation.

It should be noted that this study doesn't involve any fire modeling. The wood is used as a fuel resource, and heat generation is provided by the defined wood temperature value. Therefore, the material specifications, size, and amount of the wood were identified in CFD modeling. An accurate model is further developed with consideration of the following steps:

1. Material designation of the stove

2. Boundary conditions' determination (Film coefficient, temperature, volume flow rate, pressure)

\section{Initial conditions' determination}

4. Mesh assignment

Identification of Predicted Mean Vote: Predicted Mean Vote (PMV) approach evaluates the occupant thermal comfort based on 7 categories as presented in Fig. 4 [15], [16]. As the scale is close to +3 or 3, the Predicted Percentage of Dissatisfied (PPD) rises. In the study, the PMV value was obtained by CFD software as it includes the PMV assessment tool. Hence, the comfort level of the occupants can be seen in any location of the building.

\section{Case study}

The case building is a hipped roof, a two-story building that has a $70 \mathrm{~m}^{2}$ gross area. There is an open gallery in the living room, and the stove is located in the center of this area. The special Russian smoke path was designed and the typical material of this architecture was defined. The specifications of the material were given in Fig. 5.

The building energy performance was calculated by energy simulation software and the film coefficient values were identified based on national TS 825 standard - Thermal Insulation Requirements [17] as given in Table 1. The same film coefficient values were defined for CFD analyses for accurate comparison in the simulations. The building energy performance analysis results give the heating demand and consumption of the building.

The building energy modeling results are important to see if the generated power from the Russian stove is enough to cover the energy demand of the case building. Besides, it should be noted that transient CFD analysis is advantageous to elaborate on temperature flow, which shows us the achievement of thermal comfort. Therefore, the operation of a Russian stove can be recommended. 


\begin{tabular}{|c|c|c|c|c|c|c|}
\hline+3 hot & +2 warm & $\begin{array}{l}+1 \text { slightly } \\
\text { hot }\end{array}$ & 0 neutral & $\begin{array}{l}-1 \text { slightly } \\
\text { cold }\end{array}$ & $-2 \mathrm{cool}$ & -3 cold \\
\hline
\end{tabular}

Fig. 4. PMV scale [16]
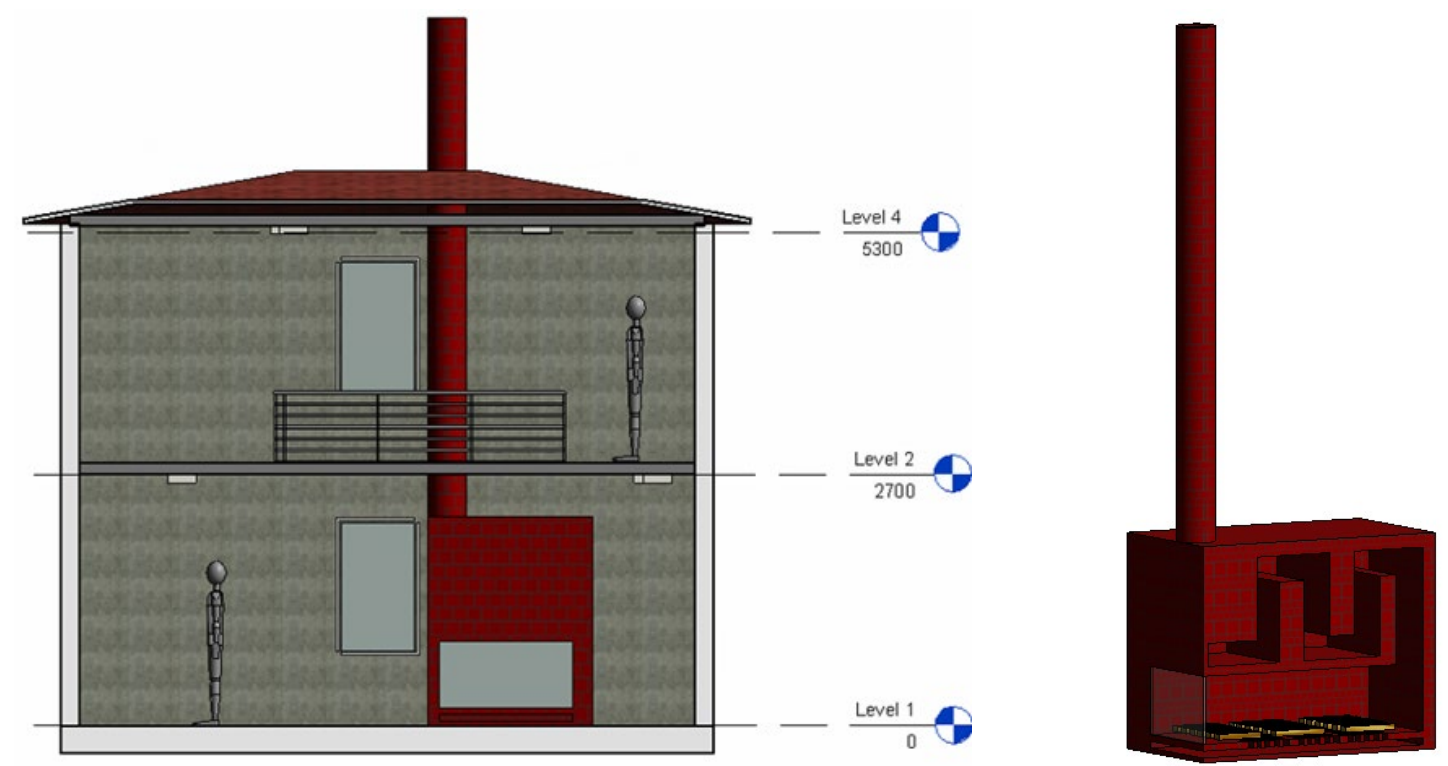

a. The section of the building with the stove location

b. Section of the three dimensioned stove

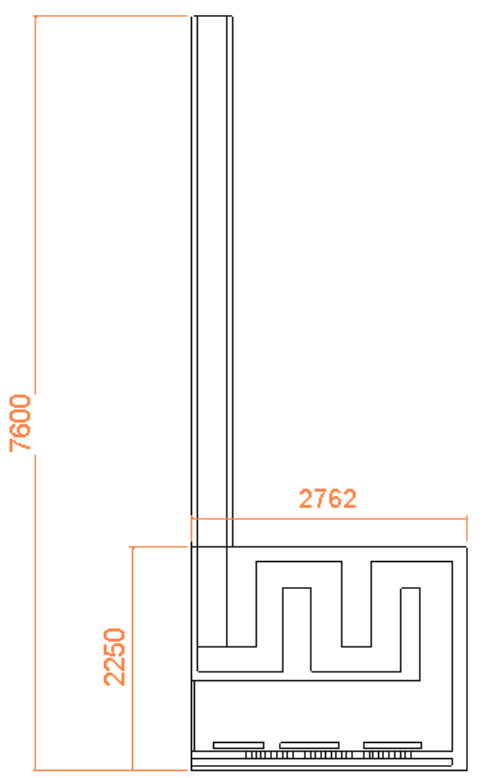

a. Two-dimensioned detail front

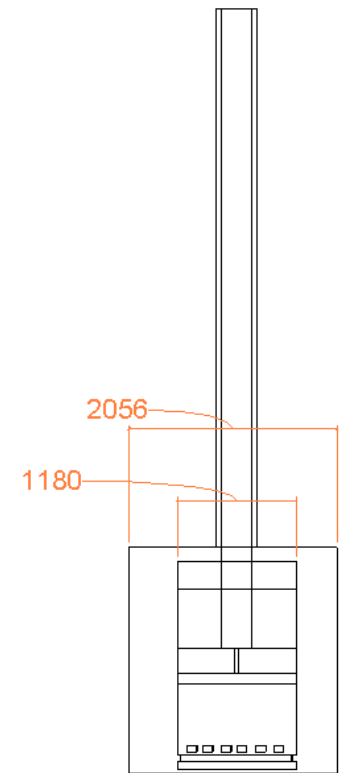

b. Two-dimensioned detail from site

Fig. 5. The specifications of the stove

Table 1. Thermal insulation requirements based on climatic regions [17]

\begin{tabular}{lllll}
\hline Region & External Wall $\left(\mathrm{W} / \mathrm{m}^{2} . \mathrm{K}\right)$ & $\operatorname{Roof}\left(\mathrm{W} / \mathrm{m}^{2} . \mathrm{K}\right)$ & Ground Floor $\left(\mathrm{W} / \mathrm{m}^{2} . \mathrm{K}\right)$ & Window $\left(\mathrm{W} / \mathrm{m}^{2} . \mathrm{K}\right)$ \\
5. Region & 0.36 & 0.21 & 0.36 & 1.8 \\
\hline
\end{tabular}


In CFD analysis, the material specification, boundary condones, initial condition, and mesh settings were defined. In the material specification step, the same materials were defined as in the building energy simulation. Brick, concrete, wood was used for the roof, external wall, and door material, respectively. The material of the Russian stove was firestone while steel casting was the comparative material for a straight chimney stove. In addition to this, the oak wood, which generates more heat output, was selected as a heating source for the heating process. The specifications of the selected materials were listed in Table 2 below.

Boundary conditions: 3-D model of the building and the masonry stove were created, and the boundary conditions were defined.

Film coefficient: The thermal properties of the building elements were given in Table 1 according to national standardization.

Temperature: The temperature change of wood was specified by the linear transient method. This method enables real-like heat generation. The temperature after 30 minutes is given in Table 3 .

Volume Flow Rate: Natural ventilation was defined by the infiltration rate in the model. The window frames were defined as the air entrance region, and this condition was determined with the volume flow rate as given in Table 4.

The energy performance is influenced by infiltration as mentioned above. In addition to the flow rate of the air entrance, the temperature of the entering air must be considered.

Table 2. The specifications of the materials [18]

\begin{tabular}{lccc}
\hline $\begin{array}{l}\text { Material/ } \\
\text { Specification }\end{array}$ & Firestone & $\begin{array}{c}\text { Steel } \\
\text { Casting }\end{array}$ & Oak \\
\hline Conductivity (W/m.K) & 1.1 & 16.2 & 0.19 \\
Density $\left(\mathrm{kg} / \mathrm{m}^{3}\right)$ & 2300 & 8000 & 760 \\
Emissivity & 0.9 & 0.54 & 0.8 \\
Specific heat (J/kg.K) & 960 & 500 & 2385 \\
\hline
\end{tabular}

Table 3. The temperature of the woods

\begin{tabular}{cc}
\hline Time $($ Seconds $)$ & Temperature $\left({ }^{\circ} \mathrm{C}\right)$ \\
\hline 0 & 12 \\
1800 & 450 \\
\hline
\end{tabular}

The case was studied based on winter conditions. Thus, the outside temperature was defined at $0{ }^{\circ} \mathrm{C}$. This condition was specified for the entering air, in addition to the volume flow rate. Besides, the pressure of the chimney outlet was defined to indicate a smoke path through the chimney.

The thermal comfort evaluation was done by the PMV tool of the software. So, the human figures were located in the building to observe the thermal comfort evaluation. Thus, the body temperature of the human figures was specified in the analysis.

\subsection{Assigning of the initial conditions}

Initial conditions determine the final results. Therefore, the initial temperature of the building elements was specified based on winter conditions (Table 5).

Following these definitions, the data importing points were located to save the temperature change during the simulation. Four points were placed on the first floor, and the other points were located on the second floor as seen in Fig. 6. The points were situated close to the corners, and the height of the points was specified as $1.4 \mathrm{~m}$ from the floor level. By these points, the occurred thermal gradient through time was examined for heating and standby period. Also, the thermal comfort level was observed by the PMV tool. Therefore, the assessment was performed at any point in the building

Table 4. Infiltration specifications of the case building

\begin{tabular}{cc}
\hline Volume Flow Rate $\left(\mathrm{m}^{3} / \mathrm{h} . \mathrm{m}^{2}\right)$ & Temperature $\left({ }^{\circ} \mathrm{C}\right)$ \\
\hline 3 & 0 \\
\hline
\end{tabular}

Table 5. Initial conditions of the computational fluid dynamics analysis

\begin{tabular}{cc}
\hline Building Element & Initial Temperature $\left({ }^{\circ} \mathrm{C}\right)$ \\
\hline External Wall & 7 \\
Roof & 7 \\
Window & 7 \\
Ground Floor & 7 \\
Ceiling & 7 \\
Indoor Air & 12 \\
\hline
\end{tabular}




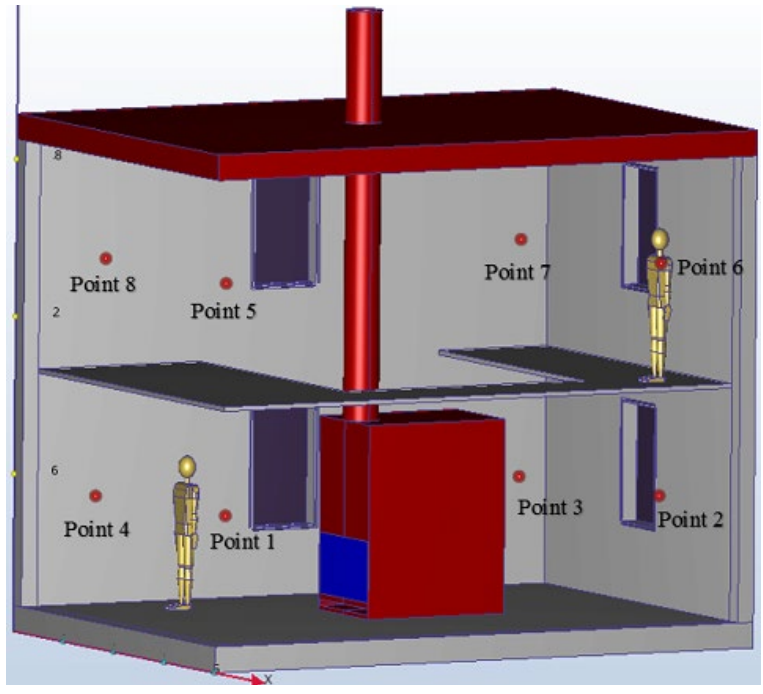

Fig. 6. The location of the points

\subsection{Development of Mesh}

In this study, the mesh independency was studied by refining the mesh in each new model. As one model finished the convergence, it was closed, and the mesh level was refined to 0.7 . After completing the convergence, the results were compared. If the result difference is more than $5 \%$, the simulation was cloned, and the mesh level was improved to 0.7 , again. This application continued until the difference was decreased to $5 \%$ in each measurement point [19], [20]. This approach enables dependability and proves the functionality of the results and the simulated model.

In the results, the models which caught the mesh independence were used. Tetrahedral geometry was used for the mesh generation. However, the prism element type formed on the wall layer.

\section{Results}

Based on the data and specifications of energy performance and CFD analyses, results were simulated and discussed in the following section.

\subsection{Energy simulation results}

The energy simulation software presents the design parameters, loads, and consumptions for each type of parameters such as cooling, heating, and lighting whilst explained in the above sections. The simulation was run for the whole year, and the thermal characteristic of the building elements was specified based on TS-825 standards. The calculated heating demand and the energy consumption of the building were given in Table 6 .

\subsubsection{Russian masonry stove's performance simulation results}

Space heating results: Eight locations were selected to obtain better assessment temperature results, as mentioned before. Besides, the heat distribution was examined inside the building. The heating process was performed for 10 hours in the case of a Russian masonry stove. After 10 hours, it was seen that the heat distributed, homogenously.

In the mesh independency step, the node numbers were increased from 340848 to 827388 , and the element number increased from 1.344.459 to 3.448 .857 .

Simulation V provides the mesh independency regarding the explained definition, above. Thus, these results were assessed to specify thermal comfort and energy efficiency (Table 7).

Predicted mean vote result for the heating period: The thermal comfort level was evaluated by PMV. PMV data were observed for 6 hours heating and 10 hours heating period, separately (Table 8 ). Hence, the impact of the temperature change based on the time was examined in detail 

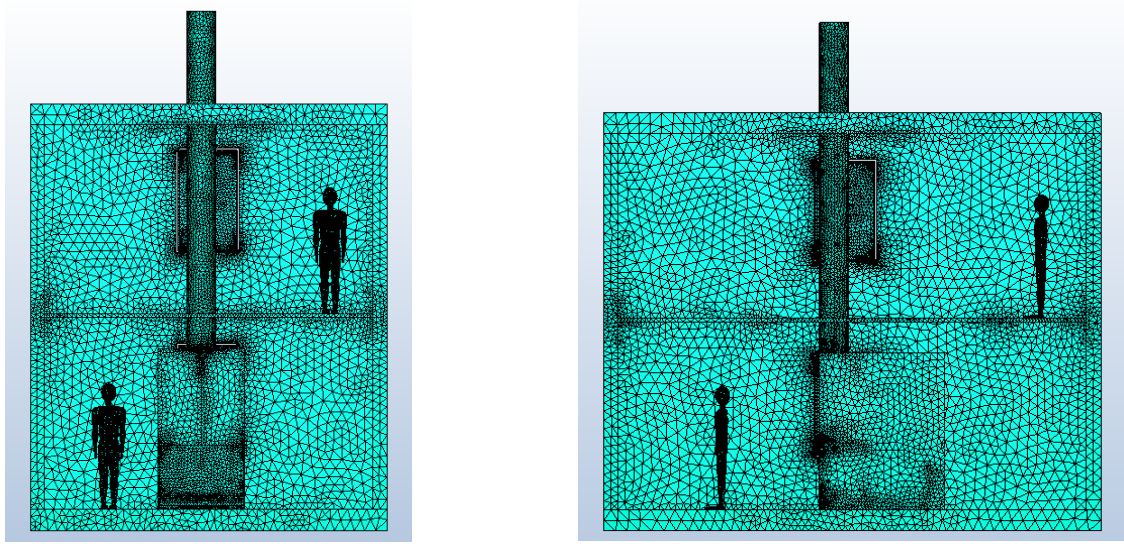

Fig. 7. The mesh view of the building from different sides

Table 6. Energy simulation results

\begin{tabular}{cc}
\hline $\begin{array}{c}\text { Zone Sensible Heating } \\
(\mathrm{kW})\end{array}$ & $\begin{array}{c}\text { Energy consumption per } \\
\text { Area }\left(\mathrm{kWh} / \mathrm{m}^{2}\right)\end{array}$ \\
\hline 14.87 & 99.22 \\
\hline
\end{tabular}

Table 7. Temperature data of the simulation $\mathrm{V}$

\begin{tabular}{cc}
\hline Point & Temperature $\left({ }^{\circ} \mathrm{C}\right)$ \\
\hline Point 1 & 24.82 \\
Point 2 & 25.40 \\
Point 3 & 21.11 \\
Point 4 & 21.45 \\
Point 5 & 23.99 \\
Point 6 & 24.90 \\
Point 7 & 24.79 \\
Point 8 & 20.28 \\
\hline
\end{tabular}

Table 8. Predicted mean vote data after the heating period

\begin{tabular}{ccc}
\hline Location & PMV (6 hours) & PMV (10 hours) \\
\hline $1^{\text {st }}$ floor & -0.2 & 0.3 \\
$2^{\text {nd }}$ floor & -0.4 & 0.1 \\
\hline
\end{tabular}

Predicted mean vote result for the standby period: After finalizing the heating period, the standby performed for 12 hours. In this duration, the temperature data were obtained from the given same eight points, identically (Table 9). As mentioned in the previous sections, simulation $\mathrm{V}$ results were used regarding the mesh independency study.

Moreover, the PMV data were evaluated based on 6 hours standby period and 12 hours standby period (Table 10).
Table 9. Temperature data of the simulation $\mathrm{V}$

\begin{tabular}{cc}
\hline Point & Temperature $\left({ }^{\circ} \mathrm{C}\right)$ \\
\hline Point 1 & 20.72 \\
Point 2 & 22.26 \\
Point 3 & 17.15 \\
Point 4 & 18.05 \\
Point 5 & 19.84 \\
Point 6 & 20.64 \\
Point 7 & 21.45 \\
Point 8 & 17.89 \\
\hline
\end{tabular}

Table 10. Predicted mean vote data after standby period

\begin{tabular}{ccc}
\hline Location & PMV (6 hours $)$ & PMV (12 hours $)$ \\
$1^{\text {st }}$ floor & -0.35 & -1.0 \\
$2^{\text {nd }}$ floor & -0.15 & -0.7 \\
\hline
\end{tabular}

4.1.2. Steel casting stove's performance simulation results

Space heating results: The same heating and standby period were performed to assess the thermal comfort and energy efficiency. The heating period of the steel casting stove was done for 6 hours. To obtain the mesh independence, the node numbers were increased from 197658 to 636309 while the element number increased from 1257844 to 2284251 . Temperature data of the simulation are given in Table 11.

Based on the presented results, mesh independence was reached in simulation $\mathrm{V}$, and the results of that simulation were chosen in the evaluation. 
Table 11. Temperature data of the simulation $\mathrm{V}$

\begin{tabular}{cc}
\hline Point & Temperature $\left({ }^{\circ} \mathrm{C}\right)$ \\
\hline Point 1 & 21.50 \\
Point 2 & 21.40 \\
Point 3 & 28.42 \\
Point 4 & 28.44 \\
Point 5 & 21.63 \\
Point 6 & 23.11 \\
Point 7 & 30.91 \\
Point 8 & 28.08 \\
\hline
\end{tabular}

Predicted mean vote result for space heating period: As in the Russian stove case, the PMV assessment was performed in the case of steel casting stove, as well. PMV evaluation was done on the first and second floors, both (Table 12).

The PMV data were specified for 6 hours heating period as the overheating was observed. If the heating was simulated for 3 hours more, PMV would reach 3 , as seen clearly.

Predicted mean vote result for the standby period: The standby period was examined for 6 hours while it was 12 hours in the Russian stove case. In this duration, the temperature data was taken from the mentioned eight points (Table 13). As explained in the previous section, simulation $\mathrm{V}$ results were evaluated regarding the independency study.

In addition to saved temperature values, the PMV data was assessed based on 6 hours standby period (Table 14).

\subsection{Discussion}

The created temperature vs time graphics shows when the thermal comfort temperature was obtained in the heating period. In these graphics, the temperature data of point 1 was taken to have a significant approach. The temperature range for the thermal comfort level is limited between $18^{\circ} \mathrm{C}$ and $24{ }^{\circ} \mathrm{C}$ in the following interpretation.

In the case of a Russian stove, $18 \mathrm{C}^{\circ}$ was obtained on the fifth hour of the heating period. The heating period was finalized in 10 hours, notwithstanding, following the next 1 hour, the temperature continued to rise. This situation is caused based on the thermal mass specification of the firestone material. In this heating duration, PMV was found as 0.3-0.1.
Table 12. Predicted mean vote data after 6 hours heating period

\begin{tabular}{cc}
\hline Location & PMV \\
\hline $1^{\text {st }}$ floor & 0.0 \\
$2^{\text {nd }}$ floor & 2.71 \\
\hline
\end{tabular}

Table 13. Temperature data of the simulation $\mathrm{V}$

\begin{tabular}{cc}
\hline Point & Temperature $\left({ }^{\circ} \mathrm{C}\right)$ \\
\hline Point 1 & 16.50 \\
Point 2 & 16.74 \\
Point 3 & 19.34 \\
Point 4 & 19.21 \\
Point 5 & 16.39 \\
Point 6 & 17.71 \\
Point 7 & 19.29 \\
Point 8 & 19.07 \\
\hline
\end{tabular}

Table 14. Predicted mean vote data after 6 hours standby period

\begin{tabular}{cc}
\hline Location & PMV \\
\hline $1^{\text {st }}$ floor & -1.4 \\
$2^{\text {nd }}$ floor & -0.4 \\
\hline
\end{tabular}

In the standby period, the temperature decrease was simulated for 12 hours. It was observed that the indoor temperature was conserved and the temperature reduced to $18{ }^{\circ} \mathrm{C}-19^{\circ} \mathrm{C}$ after 12 hours. In addition to this, the PMV value was seen around $-1 \sim-0$.

In the case of a steel casting stove, the heating period proceeded for 6 hours. $18 \mathrm{C}^{\circ}$ was caught after 4.5 hours heating period. The maximum temperature was found as $21.5 \mathrm{C}^{\circ}$. After the heating period, the standby period was simulated for 6 hours. In this period, it was seen that the temperature reduced from $21.5 \mathrm{C}^{\circ}$ to $18 \mathrm{C}^{\circ}$ in 4 hours. When 6 hours standby period was finalized, the temperature was $16 \mathrm{C}^{\circ}$, nearly. PMV was found around 2.71 in the heating period which is high when considering thermal comfort evaluation.

In the standby period, the temperature dropped very quickly as the fast increment in the heating period, and it was observed that the indoor temperature was conserved and the temperature was reduced to around $16{ }^{\circ} \mathrm{C}-19{ }^{\circ} \mathrm{C}$ after 6 hours. Furthermore, PMV was measured between -1.4 and -0.4 . 


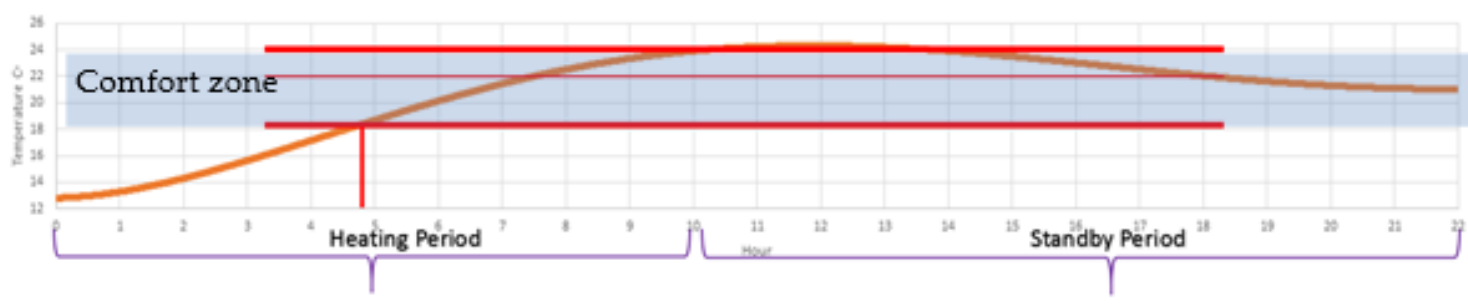

Fig. 8. Temperature-time graph for Russian stove

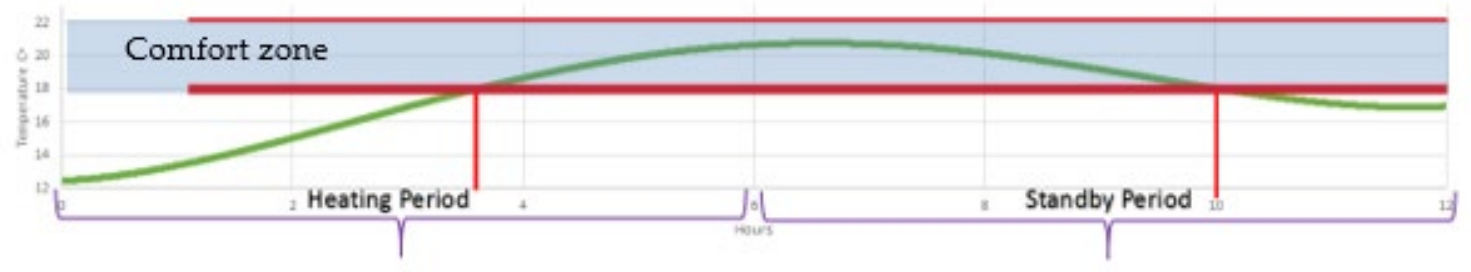

Fig. 9. Temperature-time graph for steel casting stove

\section{Conclusion}

A comparative analysis of the Russian stove and steel casting stove was achieved by utilizing CFD and energy simulations to figure out the comfort level and energy performance. In the case of the steel casting stove, the indoor temperature was increased very fast, and heterogeneous temperature distribution was observed during the heating period. In the Russian stove case, the indoor temperature went up very slowly during 10 hours heating period, and the desired temperature levels were obtained. The results of the research uncovered that:

- The thermal mass feature of the firestone was revealed out by the lower temperature change in a longer period. In the case of the Russian stove, the temperature reduced around $3{ }^{\circ} \mathrm{C}$ in 10 hours while the change was $4.5^{\circ} \mathrm{C}$ in 5 hours for the steel casting stove.

- The importance of smoke path geometry was evaluated by an S-shaped chimney design. The S-shaped helped to keep the smoke inside the fireplace that it increased the heat transfer amount from smoke to the chimney core. Therefore, the heat release continued after turning off the heating and the indoor temperature increased $1{ }^{\circ} \mathrm{C}$ in the case of a Russian stove while the indoor temperature reduced after stopping the heating operation in the steel casting stove case.

- The heat demand of the building was presented by building energy simulation that the Russian stove can be installed in contemporary buildings that have the same thermal specifications and climate conditions. By the presented comparative analysis, the thermal comfort performance was found 2 scales better in heating period by PMV scale in the case of Russian stove.

- The detailed evaluation was achieved by applying three modelings in sequences of the proposed methodology's steps as architectural, energy, and CFD, together.

This research states the collaborative work of the various disciplines like architecture, material science, and mechanical engineering to develop an effective example for an energy-efficient heating system that requires to examine by detailed threedimensional modeling, thermal energy analysis, and computational fluid dynamics analysis. For future works, the integration of this system to the multi-story apartment building might be investigated. 


\section{Declaration of conflicting interests}

The author(s) declared no potential conflicts of interest with respect to the research, authorship, and/or publication of this article.

\section{Acknowledgments}

The thesis work was conducted within the framework of the project 'Geleneksel Rus Şöminesi Isıtma Sisteminin Günümüz Mimarisinde Isı Akış Modellemesi funded by Istanbul Technical University - Bilimsel Arastirma Projeleri Koordinasyon Birimi with the project ID: 40830.

\section{References}

[1] European Energy Agency. Final energy consumption by sector and fuel., 2015. doi:CSI 027/ENER 016.

[2] Eurostat, Manual for statistics on energy consumption in households. 2013.

[3] http://sites.google.com/site/ae390assign5/stove. Acessed at March 2019.

[4] Matesz K. Masonry Heaters, Chelsea Green Publishing, Vermont, 2018.

[5] Skreiberg Ø, Georges L (2017) Wood stove material configurations for increased thermal comfort. Energy Procedia, 142: 488-494.

[6] Georges L, Skreiberg Ø, Novakovic V (2014) On the proper integration of wood stoves in passive houses under cold climates. Energy and Buildings, 72: 87-95.

[7] Tabet F, Fichet V, Plion P (2016) A comprehensive CFD based model for domestic biomass heating systems. Journal of the Energy Institute, 89(2): 199-214.

[8] Varunkumar S, Rajan NKS, Mukunda HS (2012) Experimental and computational studies on a gasifier-based stove. Energy Conversion and Management, 53(1): 135-141.

[9] Athanasios N, Nikolaos N, Nikolaos M, Panagiotis G, Kakaras E (2015) Optimization of a log wood boiler through CFD simulation methods. Fuel Processing Technology, 137: 75-92.

[10] Prapas J, Baumgardner ME, Marchese AJ, Willson B, DeFoort M (2014) Influence of chimneys on combustion characteristics of buoyantly driven biomass stoves. Energy for Sustainable Development, 23: 286-293.
[11] Carvalho RL, Vicente ED, Tarelho LAC, Jensen OM (2018) Wood stove combustion air retrofits: A low-cost way to increase energy savings in dwellings. Energy and Buildings, 164: 140-152.

[12] Hanley PM, Saez D, Nielson C, Warneck H Efficiency Study of a Contraflow Masonry Wood Burning Heater, 2005.

[13] Autodesk Help, Turbulence, Autodesk Knowledge Network, 2018.

[14] Samuelsson H. CFD Modeling and Design of an Air Heater Mixing System in a Gypsum Board Dryer, Linköping University, 2015.

[15] ANSI/ASHRAE Standard 55. Thermal Environmental Conditions for Human Occupancy, Atlanta, GA, 2010.

[16] Fanger PO. Thermal comfort. Analysis and applications in environmental engineering. New York: McGraw-Hill, 1970.

[17] Turkish Standards Institution. TS825 Thermal insulation requirements for buildings, 2014.

[18] Cardarelli F. Materials Handbook. London: Springer London, 2008.

[19] Autodesk Support, How do I know that I have a good mesh? (CFD), Autodesk Knowledge Network, 2016.

[20] Stout RP, Billings D. Accuracy and Time Resolution in Thermal Transient Finite Element Analysis, 2002. 